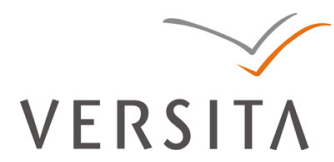

Folia Oeconomica Stetinensia

DOI: $10.2478 /$ foli-2013-0013

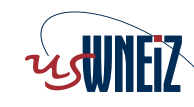

Wydzial Nauk Ekonomicznych i Zarządzania
Uniwersytetu Szczecińskiego

\title{
A PROFILE OF ROMANIAN HIGHLY EDUCATED ECO-CONSUMERS \\ INTERESTED IN PRODUCT RECYCLING. \\ A STATISTICAL APPROACH
}

Mihaela Simionescu, Ph.D.

Romanian Academy

Institute for Economic Forecasting

Casa Academiei, Calea 13 Septembrie 13, sector 5, 050711, Bucharest, Romania,

e-mail:mihaela_mb1@yahoo.com

Received 3 September 2013, Accepted 22 December 2013

\begin{abstract}
The objective of this research is to create a profile of the Romanian eco-consumer with university education. The profile is not limited to the information regarding environmental and economic benefits of recycling, but focuses on ecological behaviour. A detailed statistical analysis was made based on a large representative sample of respondents with secondary and university education. Indeed, the tendency of practical ecobehaviour becomes more pronounced for the people with university education. For people that are more than 30 years old the chance of being aware of the significance of the recycling symbols on the packages decreases, the lowest chance being given to people aged more than 50 . The respondents that are interested in environment protection buy products with ecological symbols. However, those people who already know the meaning of these symbols do not buy this type of products for ecological reasons, even if they are interested in the environment protection. This research also offers an extensive description of its results, being an opportunity for the respondents to know more about the meaning of the recycling symbols. The results of this research also provide information being a guideline for consumers. This study achieves two main goals: the ecological component (the eco-consumers were identified and ordinary consumers were attracted through the ecological behaviour) and the economic aspect (the resources allocation will be more efficient and the marketers will be able to address eco-consumers who have specific characteristics).
\end{abstract}

Keywords: eco-consumer, ecological behaviour, statistical methods, recycling symbols, multinomial regression.

JEL classification: Q5, Q570, C120, C140. 


\section{Introduction}

The objective of our study is to discover a profile of the Romanian university educated consumers interested in ecological behaviour who buy products that have packages with ecological symbols related to the recycling process. This research is a novelty in Romania, studies in this field have never been made before. Some important and innovative conclusions for were formulated using a solid statistical analysis on a representative sample of 500 respondents with secondary and university education. What is really interesting is that higher the level of education, higher the interest for an ecological behavior. More than $80 \%$ of the respondents were interested in environment protection, but their decision to buy an ecological product that promoted recycling was not influenced by their concern for environment.

\section{Literature}

The environmental attitude is a very good predictor of the ecological behaviour of a person. The environmental attitude is very well linked with the knowledge regarding ecological aspects ${ }^{1}$. In our study one of them is the information related to the meaning of ecological symbols on packages.

In our research we want to check if the degree of information regarding the ecological symbols on packages will determine ecological behaviour. In other words, we want to check if people act in an ecological way because they know more about it. Some studies in literature proved that environmental concern is not correlated with people's decision to act in an ecological manner. Some authors did not find any correlation between environmental behaviour and to what extent people recycled ${ }^{2}$. It is clearly stated that environmental concern motivates people in general to put in an extra effort. The pro-environmental behaviour is determined by environmental values and attitudes and situational factors ${ }^{3}$. We can add that these values and attitude are related to the past experience, to the information regarding ecological problems. Some authors showed some environmental dilemmas. In some cases the moral motivation determined a practical ecological behaviour, while in other cases other factors determined an ecological concern, the moral aspect being absent ${ }^{4}$. This moral motivation implies two dimensions: a social and a personal dimension that are correlated. The social dimension shows how people act in a specific situation. The personal dimension refers to internalisation of social norms and it works as a personal obligation. The moral factor was highly correlated with proenvironmental behaviour ${ }^{5}$. There are authors that claimed that situational conditions were the real cause of the variation in the norm strength ${ }^{6}$. The experience regarding ecological behaviour, 
even some theoretical information about it, will determine people to continue or to begin this behaviour. This suggestion is also demonstrated by other authors and also by this study.

There are some quantitative studies that created a profile of people interested in ecological consumption. The conclusion was that these people have secondary or university education and are interested in expressing their political or ethical views. Most of them are women with families and children, having income that is average or above the average. They live in North Europe or North America. We have attempted to make a profile of ecological consumers for a developing country such as Romania, but we chose people with secondary or university education as the subject of our observation.

The information strategy regarding the consumers' lifestyles makes them aware of the ecological consequences of their habits and of the consumption behaviour. On the other hand, the consumer should be cautious about the consequences of their buying behaviour and they should be ready to change the habits in order to put in practice the solutions for environment protection ${ }^{7}$. Some authors explained that the ecological products are actually a social responsibility of the producers $^{8}$.

\section{Methods and results}

The packaging is a part of the product strategy. However, some marketers believe that the package is the fifth element of the classical mix, together with promotion, location, product and price ${ }^{9}$. The sample in this research covers people with secondary and university education. In this category of people the degree of knowledge regarding ecological problems and ecological strategies in an economical approach is higher compared to low-educated individuals. The questionnaire plays also a positive role in educating people regarding ecological behaviour, as they are more open for knowledge even in the ecological field.

The packaging recycling is an ecological way of protecting the environment. But we have to know if the people are informed about the meaning of the recycling symbols on the packages.

The purpose of this study is to check if a representative sample consisting of the highly educated people is informed about the meaning of the ecological symbols on the packages related to recycling. Moreover, their ecological behaviour is examined to see if this knowledge is a source of motivation making people act in an ecological way. 
The logical model that we try to construct in this article is as follows:

Information regarding the ecological symbols in recycling

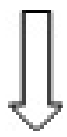

Manifestation of ecological behaviour

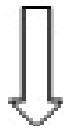

Future directions

(interest in information regarding the meaning of symbols, a guide of ecological economics, the educational role of the questionnaire).

The statistical methods used in this research include logistic regression and non-parametric tests.

Logistic regression measured the impact of more independent (exogenous) characteristics that appear simultaneously in order to predict membership of one or other category of the two dependent characteristics. The dependent variable is categorical and the exogenous ones are categorical or a mix of continuous and categorical.

There are some important advantages of the logistic or multinomial regression: some assumptions are not taken into consideration (the errors non-correlation, the normality or homoscedasticity of the independent variables). However, the maximum likelihood estimation method is used instead of the ordinary least squares.

The dependent variable takes values between 0 and 1 and the independent one (X) takes real values; $p$ denotes the probability that a case falls in a certain category. The odds ratio of an event (likelihood ratio) is $p /(1-p)$. The $\log$ of the odds ratio is $\ln \frac{p}{1-p}=b_{0}+b_{1} X+\varepsilon$. The parameters that should be estimated are $b_{0}$ and $b_{1}$. The error is denoted by $\varepsilon$.

The $\mathrm{p}$ is determined as: $p=\frac{e^{b_{0}+b_{1} X+\varepsilon}}{1+e^{b_{0}+b_{1} X+\varepsilon}}$. The estimated parameters are: $\widehat{b_{0}}$ and $\widehat{b_{1}}$.

An odds ratio (OR) equal to one shows that if $\mathrm{X}$ increases by a unit, the odds remain the same. In other words, $\mathrm{X}$ does not influence the dependent variable $\mathrm{Y}$.

An OR higher than 1 implies the following: an increase by one unit in the exogenous variable determines a growth by $e^{\widehat{b_{1}}}$ in the level of the dependent variable. If OR is lower than 1 , we will have a decrease by $e^{\widehat{b_{1}}}$ in the dependent variable. 
The Wilcoxon Signed Ranks test or other nonparametric tests could be used when the series distribution is not normal or when the type of repartition is not known ${ }^{10}$. These parametric procedures give good results regarding differences between populations when the assumptions regarding the population are not fulfilled.

In the case of our sample we do not know the shape of distribution, the appliance of nonparametric tests being the best choice.

The Wilcoxon Signed Ranks test is used to compare the means of two populations or to make inferences about the population mean. It is based on a random selection and a symmetric distribution. The variable is measured on a scale that is at least an ordinal one. The set hypothesis assumes that the null assumption (H0) implies the equality between the medians of the two samples $\left(\theta=\theta_{0}\right)$. If $\mathrm{H} 0$ is accepted, then the samples come from the same population. The alternative hypothesis states that there are differences between the sample medians $\left(\theta \neq \theta_{0}\right.$, $\theta>\theta_{0}$ or $\theta<\theta_{0}$ ).

Using the sample with " $n$ " observations $(x 1, x 2, \ldots, x n)$, the difference scores are computed: $D_{i}=x_{i}-\theta_{0}, i=1,2, \ldots, n$.

The difference scores data series has an ascending order and the ranks are assigned to $\left|D_{i}\right|$, $i=1,2, \ldots, n$. Null scores are removed from the analysis.

We denote by $\mathrm{W}$ the sum of the positive ranks. The test statistic is:

$$
Z=\frac{W-\frac{n(n+1)}{4}}{\sqrt{\frac{n(n+1)(2 n+1)}{24}}}
$$

If the p-value corresponding to this statistic is less than 0.05 , then the H0 is rejected. So, the samples come from different populations or there are statistically significant differences between the two samples (or the two variables in the analysis).

In our research all the conclusions drawn using the data from our survey are guaranteed with a probability of $95 \%$ (a significance level of 0.05 ).

The Kruskall-Wallis test is used to compare two or more populations. The null hypothesis tests that the medians of the populations are equal. If at least two medians are different the alternative hypothesis is accepted. Actually, in this case, we do not have reasons to accept the null hypothesis. The interest variable is not necessarily a numerical one and the factors that may affect it are independent. The assumptions of normality and homoscedasticity are not checked when the test is applied. If the statistic test is lower than 0.05 , the null hypothesis is rejected and 
the alternative one is accepted. So, there are differences between the populations or the interest variable does not depend on the specified factors.

For samples of low volume you may wish to refer to tables of the statistic but the chisquare approximation is better in most cases than the Kruskal-Wallis test.

The method used to collect the data is the questionnaire applied to people with high education: $\mathrm{PhD}$ professors, students, MA students, $\mathrm{PhD}$ students, engineers, physicians, managers. The sample size is 500 people from Romania. The data were processed using SPSS software for statistical analysis. 5 categories of people were identified according to their studies: 1 - PhD professors, 2 - physicians, 3 - engineers, 4 - managers, 5 - all types of students. Except the professors, all the other respondents did not have a $\mathrm{PhD}$ degree. We used non-parametrical methods, a special class of statistical methods, because we do not make assumptions regarding the characteristics of statistical distributions. However, the normal repartition could be assumed, because of the high volume of samples.

Age - the categorial variable with 5 categories: 1 (19-30 years), 2 (31-40 years), 3 (41-50 years), 4 (51-60 years) and 5 (61 years and more).

Interest in the environment protection - the binary variable with the alternatives: No (0) and Yes (1). This variable shows if the person is interested or not in the environment protection.

Knowing_symbol - the binary variable with the alternatives: No (0) and Yes (1). This variable shows if the person knows the ecological symbols regarding the package recycling, these symbols are drawn in the questionnaire.

Ecological concern - the binary variable with the alternatives: No (0) and Yes (1). This variable shows if the person is preoccupied by ecological problems or demonstrates an ecological behaviour.

Decision_of_buying - the alternative variable with the variants: Yes (1) and No (0). It refers to the decision of buying a product that ensures the environment protection.

Concern - the alternative variable with the variants: Yes (1) and No (0). It refers to the concern for environment protection when someone buys a product.

Buy_in_online_envionment - the alternative variable that refers to the decision of a consumer to buy or not a product in an online environment.

Symbol_significance - the binary variable with values: 1 (the person knows the meaning of ecological symbols in general) and 0 (the person does not know the meaning of ecological symbols in general). 
Table 1. The distribution of respondents according to their interest in environment protection

\begin{tabular}{|c|c|c|c|c|c|}
\hline \multicolumn{6}{|c|}{ Interest_in_environment_protection } \\
\hline & & Frequency & Percent & Valid Percent & Cumulative Percent \\
\hline \multirow[t]{3}{*}{ Valid } & No & 13 & 2.6 & 2.6 & 2.6 \\
\hline & Yes & 487 & 97.4 & 97.4 & 100.0 \\
\hline & Total & 211 & 100.0 & 100.0 & \\
\hline
\end{tabular}

Source: own research.

More than $97 \%$ of the selected respondents were interested in problems regarding the environment protection. Only $2.6 \%$ of the people considered the environment concern not to be their priority.

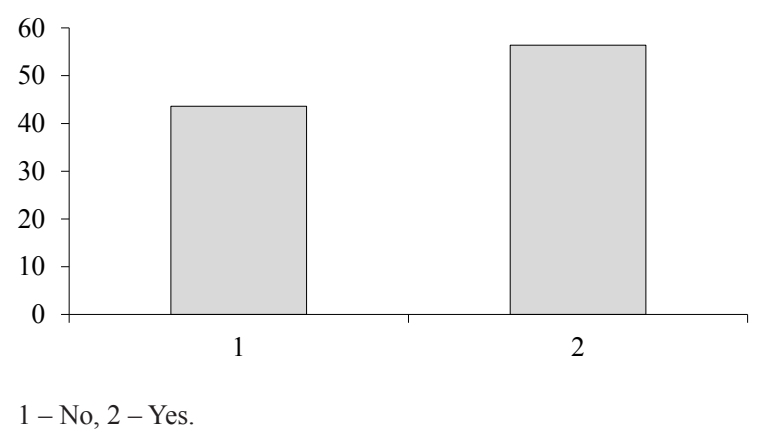

Fig. 1. The percentage of respondents that segregate waste Source: own research.

More than half of the respondents (56.4\% of them) were involved in activities of waste segregation.

The difference in percentage between the people that segregated waste and those who did not segregate waste seems to be non-significant. Therefore, a z-test is applied to check if there is a statistical difference guarantee with a probability of $95 \%$.

The hypotheses of one-tailed z-test are:

$\mathrm{H} 0$ : there is no significance difference between the percentage of people that segregated waste and the percentage of people that did not segregate waste $\left(\pi_{1}=\pi_{2}\right)$.

H1: a higher percentage of people segregated waste $\left(\pi_{1}>\pi_{2}\right)$ :

$$
z_{\text {calculated }}=\frac{\left(p_{1}-p_{2}\right)-\left(\pi_{1}-\pi_{2}\right)}{\sigma_{p_{1}-p_{2}}}=0.080599
$$

$\sigma_{p_{1}-p_{2}}=$ standard deviation of the percentages' differences. 
The standard deviation is not known and an estimator based on samples will be used: $S_{p_{1}-p_{2}}$

$$
\begin{aligned}
& \hat{\sigma}_{p_{1}-p_{2}}=S_{p_{1}-p_{2}}=\sqrt{\bar{p} \times \bar{q} \times\left(\frac{1}{n_{1}}+\frac{1}{n_{2}}\right)} \quad \bar{p}=\frac{n_{1} \times p_{1}+n_{2} \times p_{2}}{n_{1}+n_{2}}=50.8192, \\
& \bar{q}=100-\bar{p} \\
& S_{p_{1}-p_{2}}=20.32768 .
\end{aligned}
$$

The computed statistic is lower than the critical value (1.96) and it implies that we do not have enough evidence to reject the null hypothesis. So, there are no significant differences between the percentage of people that segregated waste and those that did not.

Table 2. The distribution of respondents according to their knowledge of ecological symbols regarding the package recycling

\begin{tabular}{|cl|c|c|c|r|}
\multicolumn{7}{c}{ Knowing_symbol } \\
\cline { 3 - 6 } \multicolumn{1}{c|}{} & Frequency & Percent & Valid Percent & Cumulative Percent \\
\hline \multirow{2}{*}{ Valid } & no & 76 & 15.2 & 15.2 & 15.2 \\
& yes & 242 & 84.8 & 84.8 & 100.0 \\
& Total & 500 & 100.0 & 100.0 & \\
\hline
\end{tabular}

Source: own research.

It is interesting that a higher percentage of people ( $84.8 \%$ respondents) knew the meaning of symbols, even if only $56.4 \%$ of them segregated waste.

It is clear that there were significantly more respondents that knew the ecological symbols meaning than those that had no information about this.

In the case of $\mathrm{PhD}$ professors the chances to be interested in ecological problems are greater at $90.9 \%$ than the chances of the students with ecological behaviour. These chances are in decrease from one category to another (physicians, engineers, managers), being $87.4 \%$, $78.1 \%, 25.7 \%$ respectively. So, the managers are less concerned about ecological behaviour compared to $\mathrm{PhD}$ professors, physicians and engineers. 
Table 3. The ecological concern (ecological behaviour) of the analysed categories

\begin{tabular}{|l|c|c|c|c|c|c|}
\hline \multicolumn{1}{|c|}{ Ecological_concern } & $\mathrm{B}$ & Std. Error & Wald & df & Sig. & Exp(B) \\
\hline Intercept & -2.725 & 0.516 & 27.866 & 1 & 0.000 & \\
[ecological_concern $=1]$ & 22.087 & 1.129 & 382.600 & 1 & 0.000 & 1.909 \\
[ecological_concern $=0]$ & $0^{\mathrm{a}}$ &. &. & 0 &. &. \\
\hline Intercept & -3.418 & 0.719 & 22.620 & 1 & 0.000 & \\
[ecological_concern $=1]$ & 22.087 & 1.423 & 240.896 & 1 & 0.000 & 1.874 \\
[ecological_concern $=0]$ & $0^{\mathrm{a}}$ &. &. & 0 &. &. \\
\hline Intercept & -1.808 & 0.341 & 28.094 & 1 & 0.000 & \\
[ecological_concern $=1]$ & 20.477 & 1.275 & 258.038 & 1 & 0.000 & 1.781 \\
[ecological_concern $=0]$ & $0^{\mathrm{a}}$ &. &. & 0 &. &. \\
\hline Intercept & -0.677 & 0.221 & 9.417 & 1 & 0.002 &. \\
[ecological_concern $=1]$ & 0.000 & 0.000 &. & 1 &. & 1.257 \\
[ecological_concern $=0$ ] & $0^{\mathrm{a}}$ &. &. & 0 &. \\
\hline
\end{tabular}

a 1 - PhD professors, 2 - physicians, 3 - engineers, 4 - managers, 5 - all types of students.

Source: own research.

The respondents were asked the following question: "How much would you care about the ecological aspects after you have been informed about the meaning of the recycling symbols?".

\begin{tabular}{|c|c|c|c|c|c|c|}
\hline 1 & 2 & 3 & 4 & 5 & 6 & 7 \\
\hline Not at all & & & & & & Very much \\
\hline
\end{tabular}

According to the results of the multinomial regression, the people that are not interested in ecological aspects have an extremely low chance (under $1 \%$ ) to be interested in the future compared to those that are already concerned about the environment. So, there is a great resistance to change in the case of this kind of people.

Table 4. The interest in environment protection according to the level of education

Parameter Estimates

\begin{tabular}{|c|c|c|c|c|c|c|c|c|c|}
\hline \multirow{2}{*}{\multicolumn{2}{|c|}{$\begin{array}{c}\text { Interest_in_environment_ } \\
\text { protection }\end{array}$}} & \multirow[t]{2}{*}{ B } & \multirow[t]{2}{*}{ Std. Error } & \multirow[t]{2}{*}{ Wald } & \multirow[t]{2}{*}{$\mathrm{df}$} & \multirow[t]{2}{*}{ Sig. } & \multirow[t]{2}{*}{$\operatorname{Exp}(B)$} & \multicolumn{2}{|c|}{$\begin{array}{c}95 \% \text { Confidence Interval } \\
\text { for } \operatorname{Exp}(\mathrm{B})\end{array}$} \\
\hline & & & & & & & & lower bound & upper bound \\
\hline & Intercept & 23.141 & 1.082 & 457.378 & 1 & 0.000 & & & \\
\hline & [studies=1] & -25.587 & 1.182 & 468.334 & 1 & 0.000 & $7.723 \mathrm{E}-12$ & $7.610 \mathrm{E}-13$ & $7.838 \mathrm{E}-11$ \\
\hline & [studies $=2]$ & -26.044 & 1.295 & 404.292 & 1 & 0.000 & $4.891 \mathrm{E}-12$ & $3.862 \mathrm{E}-13$ & $6.193 \mathrm{E}-11$ \\
\hline & [studies $=3]$ & -26.831 & 1.437 & 348.481 & 1 & 0.000 & $2.225 \mathrm{E}-12$ & $1.330 \mathrm{E}-13$ & $3.722 \mathrm{E}-11$ \\
\hline & [studies $=4]$ & -27.414 & 0.000 & . & 1 & . & $1.242 \mathrm{E}-12$ & $1.242 \mathrm{E}-12$ & $1.242 \mathrm{E}-12$ \\
\hline & [studies $=5]$ & $0^{\mathrm{a}}$ & . & . & 0 & . & . & . & . \\
\hline
\end{tabular}

${ }^{a}$ The reference category is: yes.

Source: own research. 
According to the multinomial regression, there is a higher chance for people with no university education not to be interested in environment protection. For example, $\mathrm{PhD}$ professors have the lowest chance of not being interested in environmental protection - almost $99 \%$ less than the interested students. Even if in the other categories the chances decreased by approximately 99\% compared to students, the percentage is still lower than that of the professors'. So, we can draw the conclusion that the higher the general education, the higher the interest in ecological behaviour in practice.

The previous conclusion is strengthened by the following result: people who do not have a $\mathrm{PhD}$ degree and who are students, managers, engineers or physicians are less likely to be interested in an ecological behaviour.

The binary logistic regression was built in order to study the relationship between the symbol awareness and the respondents' age. Six age categories were distinguished, the youngest being 21-30 year olds.

Table 5. The knowledge of symbols' meaning according to the respondents' age

Parameter Estimates

\begin{tabular}{|c|c|c|c|c|c|c|c|}
\hline & owing_symbol ${ }^{\mathrm{a}}$ & B & Std. Error & Wald & df & Sig. & $\operatorname{Exp}(B)$ \\
\hline \multirow[t]{6}{*}{$\mathrm{N}$} & Intercept & -19.985 & 0.626 & 1018.519 & 1 & 0.000 & \\
\hline & {$[$ age $=1]$} & 0.000 & 6593.167 & 0.000 & 1 & 1.000 & 1.000 \\
\hline & {$[$ age $=2]$} & 18.515 & 0.682 & 737.989 & 1 & 0.000 & $1.098 \mathrm{E} 8$ \\
\hline & [age $=3]$ & 18.717 & 0.731 & 655.403 & 1 & 0.000 & $1.345 \mathrm{E} 8$ \\
\hline & [age $=4]$ & 17.395 & 0.866 & 403.194 & 1 & 0.000 & 35.208 \\
\hline & [age $=5]$ & 18.251 & 0.000 & & 1 & . & 84.431 \\
\hline
\end{tabular}

a The reference category is: yes.

Source: own research.

For the respondents falling into the categories of 31-40 and 41-50, the chances to not know the symbol meaning decrease by more than $1 \%$, while the people aged between 51 and 60 , there are more likely not to know the symbol.

Table 6. Correlation between interest in environment protection and the intention to have an ecological behaviour

\begin{tabular}{|c|c|c|}
\hline \multicolumn{3}{|c|}{ Test Statistics } \\
\hline & Interest_in_environment_protection & Intention \\
\hline Chi-Square & $180.213^{\mathrm{a}}$ & $23.782^{b}$ \\
\hline Df & 1.000 & 6.000 \\
\hline Asymp. Sig. & 0.000 & 0.001 \\
\hline
\end{tabular}

Source: own research. 
The intention to buy products with ecological symbols is positively correlated to the expressed interest in environment protection, a chi-square test showing this relationship.

Table 7. The Kruskal-Wallis test to check the way in which the knowledge of symbols meaning influences the decision to buy the product

Test Statistics ${ }^{\mathrm{a}, \mathrm{b}}$

\begin{tabular}{|l|c|}
\cline { 2 - 2 } \multicolumn{1}{c|}{} & Decision_of_buying \\
\hline Chi-Square & 3.736 \\
Df & 1.000 \\
Asymp. Sig. & 0.053 \\
\hline
\end{tabular}

${ }^{\text {a }}$ Kruskal Wallis Test.

${ }^{\mathrm{b}}$ Grouping Variable: symbol_significance.

Source: own research.

The Asymp. Sig. being greater than 0.05 (the threshold), we can conclude that if the buyer knows already the ecological symbol meaning, it does not influence their decision to buy.

Table 8 . The results of Wilcoxon test

\begin{tabular}{|l|c|}
\cline { 2 - 2 } \multicolumn{1}{c|}{} & Concern \\
\hline$Z$ & -10.648 \\
\hline Asymp. Sig. (2-tailed) & 0.000 \\
\hline
\end{tabular}

Source: own research.

According to a non-parametric test, the Wilcoxon test, confirm that the respondents that know the meaning of the ecological symbols included in the questionnaire have a positive attitude regarding the environment protection by recycling.

Table 9. The Kruskal-Wallis Test to check the correlation between the knowledge of symbol meaning and the decision to buy a product in an online environment

Test Statistics ${ }^{\mathrm{a}, \mathrm{b}}$

\begin{tabular}{|l|c|c|}
\cline { 2 - 3 } \multicolumn{1}{c|}{} & Buy_in_online_environment & Symbol_significance \\
\hline Chi-Square & 0.069 & 3.627 \\
df & 1.000 & 1.000 \\
Asymp. Sig. & 0.792 & 0.057 \\
\hline
\end{tabular}

${ }^{a}$ Kruskal Wallis Test.

Source: own research. 
The source of knowledge of the symbol meaning does not influence the way of tracing the products in an online environment, the asymptotic significance being 0.057 , which is greater than 0.05 .

The characteristics of an Romanian well educated eco-consumer are a very good indicator that covers two objectives: ecological behaviour and a profitable business for marketers that will allocate efficiently the resources in order to reach a specific target group of consumers.

\section{Conclusions}

The profile of the Romanian well educated eco-consumer interested in recycling is a key factor of an efficient economy. The marketers that know this profile will adjust their products to the characteristics of an eco-consumer. Therefore, we have an efficient allocation of the resources and also a better environmental protection, the ecological component gaining a lot.

It is important to have marketers that create recyclable products for well educated people that are informed about the meaning of the ecological symbols. People older than 30 are less informed, so an information campaign would be necessary in order to enlarge the target group. Statistical tools are indeed a very precious mean for the researcher who wants to create an ecoconsumer profile. In Romania, this research subject is a novelty, only some aspects being in common with the developed northern countries of Europe and America.

\section{Notes}

${ }^{1}$ Kaiser et al. (1999).

${ }^{2}$ Oskamp et al. (1998).

${ }^{3}$ Corraliza, Berenguer (2000).

${ }^{4}$ Biel et al. (1999); Von Borgstede et al. (1999).

5 Stern et al. (1999).

${ }^{6}$ Biel et al. (1999).

7 Calomarde (2000).

${ }^{8}$ Poţincu, Poţincu (2012).

${ }^{9}$ Kotler, Keller (2009).

${ }^{10}$ Bratu (2012). 


\section{References}

Biel, A., von Borgstede, C., \& Dahlstrand, U. (1999). Norm perception and cooperation in large-scale social dilemmas. In: M. Foddy, M. Smithson, S. Schneider \& M. Hogg (Eds.) (2013), Resolving social dilemmas: Dynamic, structural, and intergroup aspects, (pp. 245-252). Philadelphia: Psychology Press.

Bratu, M. (2012). Strategies to Improve the Accuracy of Macroeconomic Forecasts in USA. Munich: LAP LAMBERT Academic Publishing.

Calomarde, J.V. (2000). Marketing ecológico. Madrid: Pirámide Publishing House.

Corraliza, J.A. \& Berenguer, J. (2000). Environmental values, beliefs, and actions: A situational approach. Environment and Behavior, 32 (1), 832-848.

Kaiser, F., Wölfing, S. \& Fuhrer, U. (1999), Environmental attitude and ecological behaviour, Journal of Environmental Psychology, 19 (1), 1-19.

Kotler, P. \& Keller, K. (2009). Management Marketing. Bucharest: Economica Publishing House.

Oskamp, S., Burkhardt, R.L., Schultz, P.W., Hurin, S., Zelezny, M. (1998). Predicting three dimensions of residential curbside recycling: An observational study. Journal of Environmental Education, 29 (1), 37-42.

Poţincu, L. \& Poţincu, C. (2012). The ecological products, a reflection of a socially responsible behaviour. Revista Calitatea-Acces la Succes, Special number of 2012, 358-363.

Stern, P.C., Dietz, T., Abel, T., Guagnano, G.A., \& Kalof, L. (1999). A value-belief-norm theory of support for social movements: The case of environmentalism. Human Ecology Review, $6(1), 81-97$.

Von Borgstede, C., Dahlstrand, U., \& Biel, A. (1999). From ought to is: Moral norms in largescale social dilemmas. Göteborg Psychological Reports, 29 (5), 10-23. 